\title{
Insight into the Modulation of Dissolved Organic Matter on Microbial Remediation of PAH-Contaminated Soils
}

\author{
Xue-Mei Han • Yu-Rong Liu • Li-Mei Zhang • \\ Ji-Zheng He
}

Received: 20 October 2014 / Accepted: 22 January 2015 / Published online: 24 February 2015

(C) Springer Science+Business Media New York 2015

\begin{abstract}
Microorganisms play a key role in degradation of polycyclic aromatic hydrocarbons (PAHs) in environments. Dissolved organic matter (DOM) can enhance microbial degradation of PAHs in soils. However, it is not clear how will the soil microbial community respond to addition of DOM during bioremediation of PAH-contaminated soils. In this study, DOMs derived from various agricultural wastes were applied to remediate the aging PAH-contaminated soils in a 90-day microcosm experiment. Results showed that the addition of DOMs offered a more efficient and persistent elimination of soil PAHs compared to the control which had no DOM addition. PAH removal effects were different among treatments with various DOMs; the addition of DOMs with high proportion of hydrophobic fraction could remove PAHs more efficiently from the soil. Low-molecular-weight (LMW) PAHs
\end{abstract}

Electronic supplementary material The online version of this article (doi:10.1007/s00248-015-0575-x) contains supplementary material, which is available to authorized users.

X.-M. Han · Y.-R. Liu · L.-M. Zhang $(\bowtie) \cdot J .-Z . H e(\bowtie)$

State Key Laboratory of Urban and Regional Ecology, Research

Center for Eco-Environmental Sciences, Chinese Academy of

Sciences, 100085 Beijing, China

e-mail: zhanglm@rcees.ac.cn

e-mail: jzhe@rcees.ac.cn

X.-M. Han

School of Resources and Environment, University of Jinan, Jinan 250100, China

X.-M. Han

Key Laboratory of Microbial Resources Collection and Preservation, Ministry of Agriculture, 100081 Beijing, China

J.-Z. He

Melbourne School of Land and Environment, University of

Melbourne, Parkville, Victoria 3010, Australia were more easily eliminated than that with high-molecularweight (HMW). Addition of DOMs significantly increased abundance of $16 \mathrm{~S}$ ribosomal RNA (rRNA), pdol, nah, and $\mathrm{C} 12 \mathrm{O}$ genes and obviously changed community compositions of $n a h$ and $C 12 O$ genes in different ways in the PAHcontaminated soil. Phylogenetic analyses of clone libraries exhibited that all of nah sequences and most of $\mathrm{C} 12 \mathrm{O}$ sequences were affiliated into Gammaproteobacteria and Betaproteobacteria. These results suggested that external stimuli produced by DOMs could enhance the microbial degradation of PAHs in soils through not only solubilizing PAHs but also altering abundance and composition of indigenous microbial degraders. Our results reinforce the understanding of role of DOMs in mediating degradation of PAHs by microorganims in soils.

Keywords Polycyclic aromatic hydrocarbon · Dissolved organic matter $\cdot$ Bioremediation $\cdot$ qPCR $\cdot$ PAH-degrading gene $\cdot$ T-RFLP

\section{Introduction}

Polycyclic aromatic hydrocarbons (PAHs) are ubiquitous chemical pollutants which can pose a threat to human health and ecosystem safety as a result of their recalcitrant, mutagenic, and carcinogenic properties and high bioaccumulation of the food chain [1-3]. Soil is the main natural reservoir of PAHs; thereby, remediation of the PAH-contaminated soil has received a lot of scientific attention in recent years [4]. Compared to the cost-intensive physical and chemical methods for cleaning up the contaminated soil, bioremediation, especially microbial biodegradation of organic pollutants, is generally believed as a cost-effective and promising 
option. However, in the microbial remediation of the soils polluted by organic compounds, the actual biodegradation is frequently limited by pollutant accessibility, i.e., their transport (e.g., diffusion) to a microbial cell attached to the external surface of the soil aggregates [5, 6]. It is well known that the sequestration of pollutants over the soil-chemical contact time (aging) may occur due to interaction of pollutant molecules with soil aggregates. Many studies have proved that the sequestration of pollutants increases significantly with time in the aging processes $[7,8]$. Thus, sorption of organic pollutant from soil aggregates, which influences the bioavailability of the contaminant, is a critical factor for microbial bioremediation of the soil contaminated by PAHs [9].

Surfactants are compounds with the capacity of lowering the surface tension between two phase systems. They can be used to enhance the bioavailability of organic pollutants by increasing the solubilization of the organic pollutants from soil to water and, as a consequence, promote microbial bioremediation of PAH-contaminated soils. The dissolved organic matter (DOM) has similar qualities to surfactants and also possesses good performance in facilitating the solubilization and transport of hydrophobic organic contaminants [10]. The term "dissolved organic matter (DOM)" refers to all organic substances smaller than $0.45 \mu \mathrm{m}$ that are suspended in aqueous solutions [11]. DOM is probably the most bioavailable fraction of organic matter in soils because organic matter must be dissolved into the water firstly and then can be consumed by soil microorganisms. Some advantages of DOM, such as low cost, readily biodegradable, nontoxic, and pollution-free compared with some synthetic surfactants, make it more attractive. Many studies revealed the sorption/desorption behaviors of PAHs in soil-water system when DOMs were added $[10,12,13]$. Although it is presumed that microbial degradation of PAHs can be enhanced through increasing the solubility of PAHs and providing the nutrients for microorganisms when adding DOM to contaminated soils, the research on effect of DOM application on microbial degradation of PAHs in soils is scant and the understanding of how indigenous PAH-degrading microbial populations respond to the external stimuli is lacking [14].

Some studies suggest that the structure and function of microbial communities will change in the period of repairing contaminated soils [15-17]. The addition of mushroom cultivation substrate enhanced the elimination of PAHs in soil microcosms and considerably stimulated the growth of bacteria, fungi, and aromatic hydrocarbon degraders as well as changed the community compositions of bacteria and fungi [18]. The DGGE profiles showed that inoculation with Sphingobium yanoikuyae B1 did not cause obvious changes in the native bacterial community but led to an increase in the intensity of two bands in the aged PAH-contaminated soil [19]. Here, it is presumed that amounts of PAH degraders and their community composition will change during remediation of PAH-contaminated soils amended with DOMs, and DOMs with various properties can have different effects on size and community composition of PAH degraders and biodegradation rate of PAHs. The information of PAH degraders can be expressed by abundance and community composition of PAH degrading-related genes using molecular ecology techniques. $\mathrm{Pdol}$, nah, and $\mathrm{C12O}$ are three important PAH-degrading genes which are widespread in soils near a coking plant [20-22] and encode the pyrene dioxygenase [23], naphthalene dioxygenase [24], and catechol 1,2dioxygenase [25], respectively. In this study, abundance and community composition of the above PAH-degrading genes and the removal efficiency of different PAHs were monitored during the bioremediation of aging PAH-contaminated soils amended with the DOM derived from various agricultural wastes. The results would contribute to remediate the aging PAH-contaminated soils through the application of biostimulation technology.

\section{Materials and Methods}

\section{DOM Preparation and Measurement}

Wheat stalk (WS), mushroom cultivation substrate waste (MCSW), and cow manure (CM) were used as sources of DOM in this study. They were collected from a farm of Tai'an city in northern China and air-dried at room temperature and ground to pass through a 1-mm mesh. Various DOMs were extracted from WS, CM, and MCSW by Milli-Q water at 1:20 $(w / v), 1: 40(w / v)$, and 1:20 $(w / v)$, respectively. The mixtures were shaken for $16 \mathrm{~h}$ at $200 \mathrm{rpm}$ on a horizontal rotator. The suspensions were then centrifuged for $20 \mathrm{~min}$ at 12 , $000 \mathrm{rpm}$ at $4{ }^{\circ} \mathrm{C}$ and passed through $0.45-\mu \mathrm{m}$ membrane filters. The dissolved organic carbon (DOC) content of DOM extracts was determined using a TOC analyzer (Liqui TOC, Elementar Co., Hanau, Germany). The hydrophilic and hydrophobic fractions of the DOM were separated by XAD-7 resin. The freeze-dried DOMs were used for $\mathrm{C}$, N, and S concentration determination with an element analyzer (Vario EL III, Elementar, Hanau, Germany) and Fourier transform infrared spectroscopy (FTIR) analysis with a FTIR spectrophotometer (NICOLET 8700, Thermo Fisher, Waltham, USA).

Soil, Microcosm, and Incubation Conditions

The soil sample was collected from a coke factory with a 6year history of coking production located in Xintai $\left(35^{\circ} 54^{\prime} \mathrm{N}\right.$, $117^{\circ} 43^{\prime} \mathrm{E}$ ) of northern China. After being sieved through 2$\mathrm{mm}$ mesh and homogenized thoroughly, the soil was divided into two subsamples. One subsample was employed to determine the physiochemical properties with the standard methods recommended by the Soil Science Society of China [26]. The 
main characteristics of the soil are shown in Table 1. The other subsample was used for microcosm experiment. The soil microcosms were set up in triplicate with the moist soil equivalent to $100 \mathrm{~g}$ of dry soil in a 480-ml polypropylene container with air-permeable cap. The DOMs containing $85 \mathrm{mg}$ of DOC from WS, MCSW, and CM after being freeze-dried and redissolved in sterile water were added into soil microcosms and homogenized thoroughly, respectively. In this study, the soil microcosms with addition of DOMs from WS, MCSW, and CM were named treatment WS, treatment MCSW, and treatment CM, respectively. The soil microcosm without DOM was used as a control. Soil moisture was adjusted to $60 \%$ of maximum water holding capacity (MWHC) and kept the same by periodic replenishment of water in the entire incubation process. Soil microcosms were kept in darkness at $28{ }^{\circ} \mathrm{C}$ with $60 \%$ relative humidity for 3 months. Ten grams of soil samples was taken on days $5,15,30,55$, and 90 from each tray to measure the content of PAHs and analyze the characteristics of microbial community.

\section{Measurement of PAH Content}

The 16 USEPA priority PAHs in the soil samples were extracted with ultrasonic extraction method recommended by the USEPA [27]. Briefly, $1 \mathrm{~g}$ of freeze-dried soil after being grounded and sieved through 100-mesh screen was extracted with $30 \mathrm{ml}$ of dichloromethane-hexane $(1: 1, v / v)$ in an ultrasonic cleaner for three times. After centrifugation, the

Table 1 Basic properties of the PAH-contaminated soil and DOMs extracted from various agricultural wastes

\begin{tabular}{|c|c|c|c|c|}
\hline & Soil & DOM-WS & $\begin{array}{l}\text { DOM- } \\
\text { MCSW }\end{array}$ & $\begin{array}{l}\text { DOM- } \\
\text { CM }\end{array}$ \\
\hline $\mathrm{pH}$ & 7.34 & - & - & - \\
\hline $\mathrm{H}_{2} \mathrm{O}(\%)$ & 10.64 & - & - & - \\
\hline MWHC (\%) & 44.51 & - & - & - \\
\hline Sand $(\%)$ & 48.32 & - & - & - \\
\hline Silt $(\%)$ & 46.8 & - & - & - \\
\hline Clay $(\%)$ & 4.88 & - & - & - \\
\hline $\mathrm{TC}\left(\mathrm{g} \mathrm{kg}^{-1}\right)$ & $38.76 \mathrm{~d}$ & $216.5 \mathrm{c}$ & $255.1 \mathrm{a}$ & $245.6 \mathrm{~b}$ \\
\hline $\mathrm{TN}\left(\mathrm{g} \mathrm{kg}^{-1}\right)$ & $1.634 \mathrm{~d}$ & $13.75 \mathrm{c}$ & $24.46 \mathrm{~b}$ & $27.06 \mathrm{a}$ \\
\hline $\mathrm{TS}\left(\mathrm{g} \mathrm{kg}^{-1}\right)$ & $1.649 \mathrm{~d}$ & $25.65 \mathrm{~b}$ & $39.14 \mathrm{a}$ & $20.32 \mathrm{c}$ \\
\hline $\mathrm{DOC}\left(\mathrm{g} \mathrm{kg}^{-1}\right)$ & 0.146 & - & - & - \\
\hline Hydrophobic part (\%) & - & $48.83 \mathrm{c}$ & $63.67 \mathrm{~b}$ & $66.09 \mathrm{a}$ \\
\hline Hydrophilic part (\%) & - & $51.17 \mathrm{a}$ & $36.33 \mathrm{~b}$ & $33.91 \mathrm{c}$ \\
\hline
\end{tabular}

Different letters following the means $(n=3)$ in the same row indicate significant differences $(P<0.01)$ between the corresponding materials

$D O M-W S$ DOM extracted from wheat stalk (WS), DOM-MCSW DOM extracted from mushroom cultivation substrate waste (MCSW), DOM$C M$ DOM extracted from cow manure (CM), $M W H C$ maximum water holding capacity supernatant from the same sample was mixed and concentrated with a rotary evaporator. PAHs were separated with a column of 100-mesh silica gel and alumina through sequential elution with $15 \mathrm{ml}$ of hexane and $70 \mathrm{ml}$ of hexane/ dichloromethane $(7: 3, v / v)$. The eluent continued to be concentrated to $1 \mathrm{ml}$ under gas flow of nitrogen.

PAHs were detected on a GC-MS system (HP7890-5975C, Agilent Technologies Inc., Wilmington, DE, USA) equipped with Agilent DB-5MS column $(30 \mathrm{~m} \times 0.25 \mathrm{~mm}$ i.d. with $0.25-\mu \mathrm{m}$ film thickness) under a flow rate of $1 \mathrm{ml} \mathrm{min}^{-1}$. Column temperature was programmed to hold $80^{\circ} \mathrm{C}$ for 2 min, ramp up to $120^{\circ} \mathrm{C}$ at $3{ }^{\circ} \mathrm{C} \min ^{-1}$, ramp up to $200{ }^{\circ} \mathrm{C}$ at $5{ }^{\circ} \mathrm{C} \min ^{-1}$, ramp up to $290{ }^{\circ} \mathrm{C}$ at $7{ }^{\circ} \mathrm{C} \min ^{-1}$, and hold $290{ }^{\circ} \mathrm{C}$ for $15 \mathrm{~min}$.

Hexamethylbenzene and a certified mixture containing 16 USEPA priority PAHs (AccuStandard, New Haven, CT, USA) were used as the internal and external standards, respectively. Identification and quantification of PAHs were based on their retention times, target and qualifier ions, and a five-point calibration curve (the ratio of external to internal standard). The recovery rate during extraction and cleanup was determined by spiked Phe-d10 into the soils $24 \mathrm{~h}$ prior to the extraction process.

\section{Soil DNA Extraction and qPCR Assays}

Total community DNA was extracted from $0.25 \mathrm{~g}$ of soil with the PowerSoil DNA Isolation Kit (MoBio Laboratories, Solana Beach, CA, USA) following the manufacturer's instruction. The concentration of the extracted DNA was measured with an UV-vis spectrophotometer (ND-1000, NanoDrop Technologies, Wilmington, DE, USA).

The bacterial $16 \mathrm{~S}$ ribosomal RNA (rRNA) and the selected PAH-degrading genes ( $p d o 1, n a h$, and $C 12 O$ ) were amplified using an iCycler iQ 5 thermocycler (Bio-Rad Laboratories, Hercules, CA, USA). The $25 \mu \mathrm{l}$ of PCR reaction buffer consisted of $2 \mu \mathrm{l}$ of template DNA (1-10 ng), $0.5 \mu \mathrm{l}$ of each primer $(10 \mu \mathrm{M})$, and $12.5 \mu \mathrm{l}$ of $2 \times$ SYBR Premix Ex Taq ${ }^{\mathrm{TM}}$ (TaKaRa Bio Inc., Dalian, China). In the PCR reaction buffer of 16S rRNA gene, the probe TM1389F was added and $2 \times$ SYBR Premix Ex Taq $^{\mathrm{TM}}$ was substituted for $2 \times$ Premix Ex $\mathrm{Taq}^{\mathrm{TM}}$ (TaKaRa Bio Inc., Dalian, China). The primer pairs, probe, and reaction conditions are listed in Table S1. Standard curves for qPCR experiments were constructed according to the procedure described by Lillis et al. [28]. Briefly, the genes of $p d o 1, n a h$, and $C 12 O$ were amplified respectively with the primer pairs and under the conditions in Table S1. The purified PCR products with a gel purification kit (Promega, Madison, WI, USA) were cloned with the pGEM-T Easy Vector system (Promega Madison, WI, USA). Plasmids of the positive clones from each target gene insert were sequenced and identified. The copy numbers of the confirmed plasmid DNA were calculated based on their concentrations. 
Tenfold dilution series of each gene were used to generate the standard curve.

\section{T-RFLP Analysis}

As the previous research by Han et al. showed that all sequences from the pdo1 gene clone library were classified into Mycobacterium [22], terminal restriction fragment length polymorphism (T-RFLP) analysis of nah and C12O genes was only selected here to determine the microbial community compositions. PCR amplifications of nah and C12O genes were done using the same procedure and primer pairs as the qPCR except 5' end of the forward primers labeled with 6carboxyfluorescein (FAM). The purified PCR products of $n a h$ and $\mathrm{C} 12 \mathrm{O}$ with a gel purification kit (Promega, Madison, WI, USA) were digested respectively with restriction enzymes Rsa I and Alu I (TaKaRa Bio Inc., Dalian, China) and Msp I (Promega Madison, WI, USA) following the manufacturer's instructions. The PCR fragments purified by ethanol precipitation were analyzed using a Genetic Analyzer (3130XL, Applied Biosystems, Foster City, CA, USA). T-RFLP profiles were obtained using the GeneMapper 3.7 software. The relative abundance of terminal restriction fragments (T-RFs) was calculated by dividing the peak area of the T-RF by that of total T-RFs in the profile. T-RFs less than $50 \mathrm{bp}$ or with a portion of less than $1 \%$ in the total T-RFs were neglected.

\section{Construction of Clone Libraries and Phylogenetic Analysis}

The PCR products of the nah or $C 12 O$ genes from the initial soil sample were purified with a gel purification kit (Promega, Madison, WI, USA). The purified PCR products were used to construct the clone libraries with the pGEM-T Easy Vector system (Promega, Madison, WI, USA) following the manufacturer's instructions, respectively. The 77 and 218 positive clones selected respectively from the nah and $\mathrm{C} 12 \mathrm{O}$ clone libraries were used for sequencing. Sequence similarity was calculated using MOTHUR (http://www.mothur.org/). Nucleotide sequences sharing a $97 \%$ identity for the nah clone library or an $85 \%$ identity for the $C 12 \mathrm{O}$ clone library were defined as one operational taxonomic unit (OTU) or one class. Only one representative sequence of each OTU or class was used for phylogenetic analyses. The sequences from GenBank similar to the representative sequences of the clone library were determined by aligning with the BLAST search program (http://blast.ncbi.nlm.nih.gov) and used to construct the phylogenetic tree together. Phylogenetic trees were constructed using MEGA version 4.0 according to the neighbor-joining method with 1000 bootstrap replications. Sequences of the nah and $\mathrm{C} 12 \mathrm{O}$ clones used in construction of phylogenetic tree were deposited in the nucleotide database of GenBank under accession numbers KM287400 to KM287409 and KM287373 to KM287399, respectively.
Statistical Analyses

The gene abundance data were log transformed for subsequent statistical analysis. Two-way analysis of variance (ANOVA) was performed to determine the significance of the effect of DOM treatment, incubation time, and their interactions on abundance of bacterial 16S rRNA and PAH-degrading genes. One-way ANOVA based on Fisher LSD test was used to examine the differences in the content of PAHs, abundance of detected genes, and ratios of abundances of PAH-degrading genes to bacterial $16 \mathrm{~S}$ rRNA gene between different treatments. A permutational multivariate analysis of variance (PERMANOVA) test with 9999 permutation was used to assess the differences of T-RFLP profile of $n a h$ and $C 12 O$ genes between different treatments. Nonmetric multidimensional scaling (NMDS) plots were drawn on the basis of BrayCurtis similarity indices of fourth-root-transformed T-RFLP data. Two-way and one-way ANOVAs were conducted using SPSS 13.0. PERMANOVA, and NMDS was performed using PRIMER6 with PERMANOVA+ package (Version 1.1.0, Plymouth, UK). Figures were drawn using OriginPro 7.5. The probability levels of $P<0.05$ and $P<0.01$ were regarded to be statistically significant.

\section{Results}

Properties of Various DOMs

The basic properties of DOMs derived from agricultural wastes are shown in Table 1. The contents of TC, TN, and TS of DOMs ranged from 216.5 to $255.1 \mathrm{~g} \mathrm{~kg}^{-1}$, from 13.75 to $27.06 \mathrm{~g} \mathrm{~kg}^{-1}$, and from 20.32 to $39.14 \mathrm{mg} \mathrm{kg}^{-1}$, respectively. There were significant differences in all chemical indexes among DOMs from WS (DOM-WS), MCSW (DOMMCSW), and CM (DOM-CM) $(P<0.01)$. Contents of all chemical parameters were sorted in descending order as follows: DOM-MCSW, DOM-CM, and DOM-WS for TC; DOM-CM, DOM-MCSW, and DOM-WS for TN; DOMMCSW, DOM-WS, and DOM-CM for TS; and DOM-CM, DOM-MCSW, and DOM-WS for proportion of hydrophobic part.

FTIR spectra for DOMs are shown in Fig. 1. The spectra were interpreted according to published results [29, 30]. DOMs derived from WS, MCSW, and CM exhibited the similar spectra. They showed a broad band at 3326-3350 $\mathrm{cm}^{-1}$, which was attributed to the $\mathrm{O}-\mathrm{H}$ stretching from phenols and carboxylic groups. Signals at 2930-2940 $\mathrm{cm}^{-1}$ from all DOMs were attributed to the $\mathrm{C}-\mathrm{H}$ stretching from methylene group. The bands at $1572 \mathrm{~cm}^{-1}$ for DOM-WS, at $1602 \mathrm{~cm}^{-1}$ for DOM-MCSW, and at $1555 \mathrm{~cm}^{-1}$ for DOM-WS were correlated to the $\mathrm{N}-\mathrm{H}$ deformation and $\mathrm{C}=\mathrm{N}$ stretching from amides II. Signals near $1426 \mathrm{~cm}^{-1}$ for all DOMs were due to 


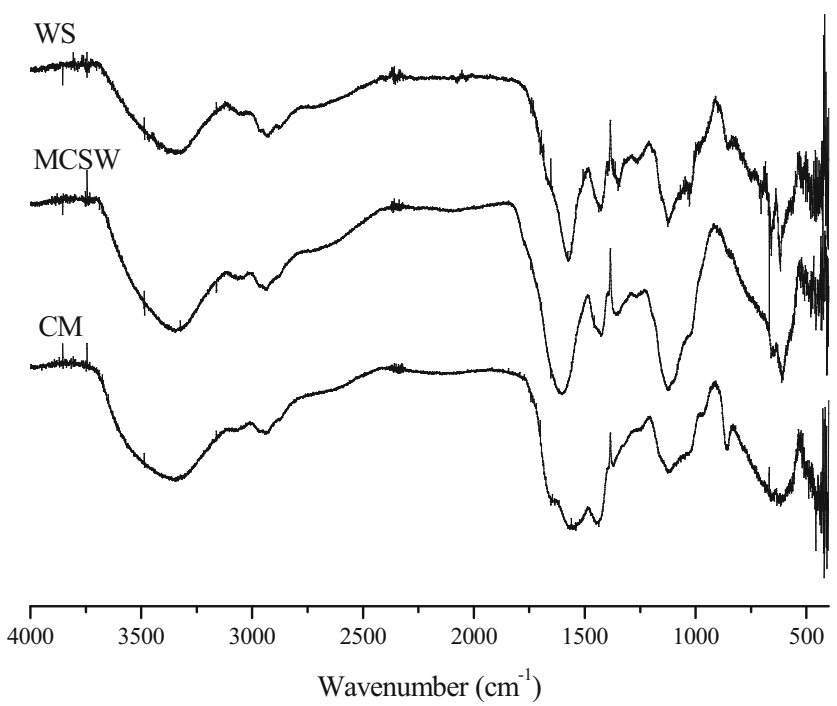

Fig. 1 FTIR spectra for DOMs extracted from wheat stalk (WS), mushroom cultivation substrate waste $(M C S W)$, and cow manure $(C M)$

the $\mathrm{COO}^{-}$stretching of carboxylic acids and $\mathrm{C}-\mathrm{N}$ stretching of amides III. Absorption peaks at $1349-1370 \mathrm{~cm}^{-1}$ for all DOMs were attributed to the $\mathrm{C}-\mathrm{N}$ stretching of aromatic primary and secondary amines. Signals near $1122 \mathrm{~cm}^{-1}$ for all DOMs were produced by the $\mathrm{C}-\mathrm{O}$ stretching of polysaccharides or polysaccharide-like substances.

\section{Impacts of DOM Treatments on PAH Degradation}

The 16 USEPA priority PAHs were detected in this study. The recoveries for standard Phe-d10 spiked into the soil samples ranged from 71.3 to $96.7 \%$. The mixture of 16 PAHs was divided into five parts based on the numbers of aromatic ring. The content of total PAHs in the initial soil was $36.06 \mathrm{mg} \mathrm{kg}^{-1}$ dry weight soil with $3.268,6.068,15.04,7.099$, and $4.586 \mathrm{mg}$ of two-, three-, four-, five-, and six-ring PAHs per kilogram dry soil, respectively. The contents of remaining PAHs in soils at days $5,15,30,55$, and 90 after adding various DOMs are illustrated in Fig. 2. The DOMs had a significant positive effect on degradation of PAHs compared with the control since 15 days of incubation $(P<0.05)$. Significant difference in levels of remaining PAHs $(P<0.05)$ was found among different DOM treatments in later period of incubation. On day 30 , only the content of PAHs in the treatment $\mathrm{CM}$ was lower than that in the treatment WS $(P<0.05)$. However, the contents of remaining PAHs were lower in both treatments MCSW and CM than that in the treatment WS on days 55 and $90(P<0.05)$. Moreover, there was less content of remaining PAHs in the treatment MCSW than that in the treatment $\mathrm{CM}$ on day $90(P<0.05)$. At the end of incubation, $20.90 \%$ of total PAHs were removed in the control while degradation yields reached $49.67-66.22 \%$ in the treatments with DOMs. The difference of elimination of PAHs with different numbers of aromatic rings was also found. For example, the degradation rates of $76.78 \%$ for two-ring PAHs and $70.50 \%$ for three-ring PAHs were achieved whereas only less than $64.80 \%$ of four- to six-ring PAHs were eliminated in treatment MCSW.

Impacts of DOM Treatments on Abundances of the 16S rRNA, pdol, nah, and C12O Genes

Abundances of the $16 \mathrm{~S}$ rRNA, pdol, nah, and $\mathrm{C} 12 \mathrm{O}$ genes in the initial soil were $4.66 \pm 1.15 \times 10^{10}, 3.13 \pm 0.48 \times 10^{9}, 2.10 \pm$ $0.63 \times 10^{6}$, and $5.06 \pm 1.69 \times 10^{6}$ copies $\mathrm{g}^{-1}$ dry weight soil, respectively. Abundances of the detected genes in the microcosms during the whole incubation period are shown in Fig. 3. The two-way ANOVA analysis showed that DOM treatments had the significant effects on abundances of pdol $(P<0.05)$, nah $(P<0.01)$, and $C 12 O(P<0.01)$. Incubation time exerted the significant influences on all of detected genes $(P<0.01)$. However, the interaction between the two factors only had the significant effect on the $n a h$ gene abundance $(P<0.01)$ (Table S2).

Further analysis of ANOVA showed that the copy numbers of the 16S rRNA gene were higher in treatments WS and CM on day 5 and treatments WS and MCSW on day 15 than that in the control $(P<0.05)$ (Fig. 3a). No significant difference of the 16S rRNA gene abundance was found between DOM treatments and the control at following sampling time. Abundance of pdol gene did not change significantly compared to the control on day 5 and day 15 . However, copy numbers of $p d o 1$ gene significantly increased in treatments WS and MCSW on day $30(P<0.05)$. Then, there was no obvious difference in $p d o 1$ gene copy numbers between DOM treatments and the control on day 55 . The significant increase of pdol gene abundance was observed again in all of DOM treatments at the end of incubation $(P<0.05)$ (Fig. 3b). For nah gene, DOM treatments significantly stimulated the increase of its abundance compared to the control during the whole incubation period $(P<0.05)$. And, significantly different nah gene abundances were also observed between different DOM treatments on day 5, day 30 , and day $90(P<0.05)$ (Fig. 3c). For $C 12 O$ gene, the addition of DOM-WS significantly increased its copy number on day 5 compared to the control $(P<0.05)$. Abundances of $C 12 O$ gene in both treatments WS and MCSW were significantly higher than that in the control on day $15(P<0.05)$. Significant increase of $C 12 O$ gene abundance in treatment $\mathrm{CM}$ was also found on day 55 $(P<0.05)$ (Fig. 3d).

During the whole incubation period, the ratios of $p d o 1$ to bacterial 16S rRNA gene abundance in treatments WS and $\mathrm{CM}$ on day 30 were significantly higher than that in the control $(P<0.01)$. For the ratio of $n a h$ to bacterial $16 \mathrm{~S}$ rRNA gene abundance, the ratios in all of DOM treatments on day 5 , treatment $\mathrm{CM}$ on day 15 , and treatments $\mathrm{WS}$ and $\mathrm{CM}$ on day 55 were higher than that in the control $(P<0.01$ for WS 
Fig. 2 Contents of PAHs in soil microcosms at different incubation periods. CK, WS, MCSW, and CM represent the control and the treatments with DOMs from wheat stalk, mushroom cultivation substrate waste, and cow manure, respectively. $-5,-15,-30,-55$, and -90 mean the incubation periods of $5,15,30,55$, and 90 days, respectively. Error bars are the $\mathrm{SD}$ of $n=3$. Different letters in the same column indicate significant differences $(P<0.05)$ of total PAH contents among different treatments on the same incubation time

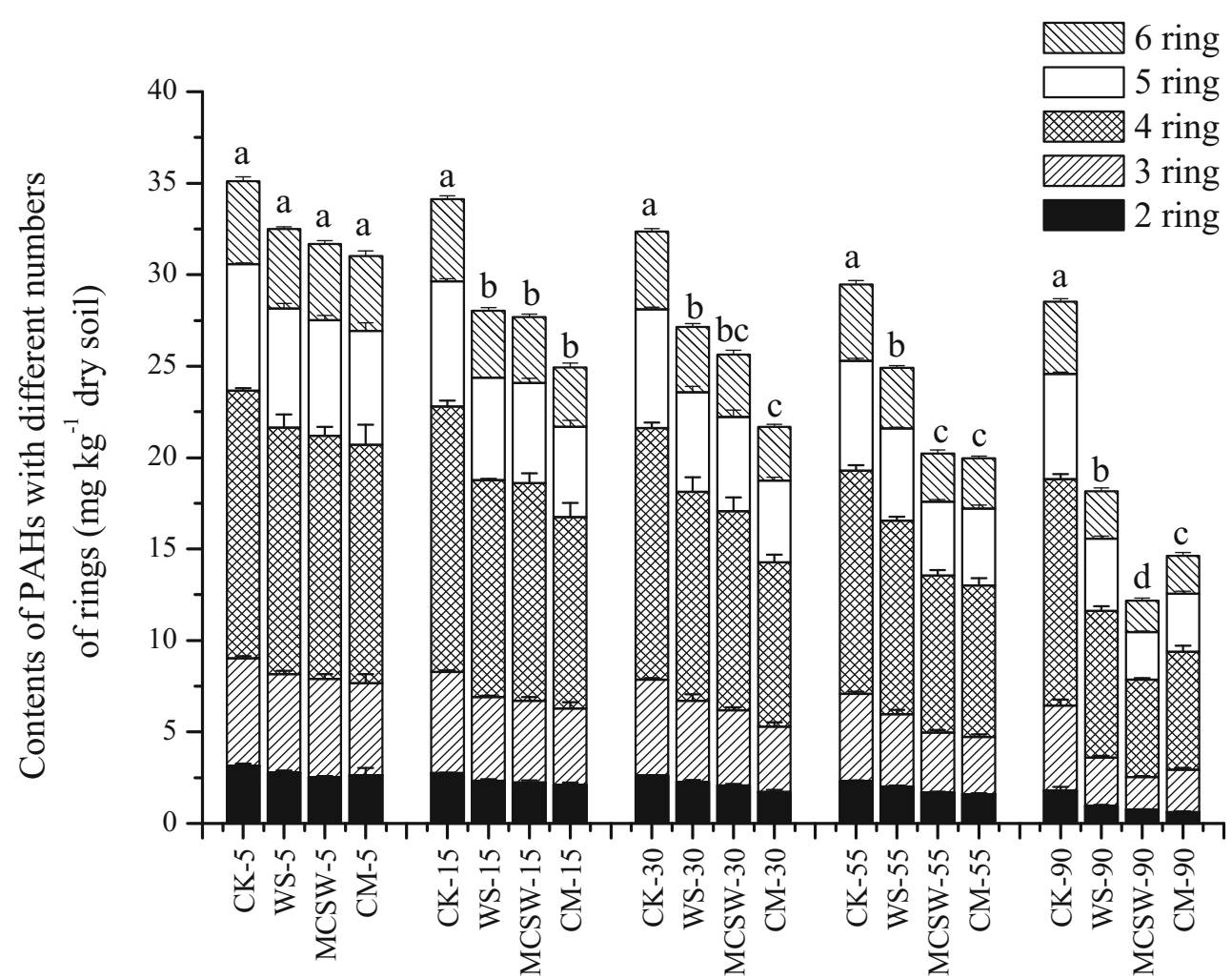

Treatments at different incubation time and MCSW on day 5, $P<0.05$ for others). The treatment WS on day $5(P<0.01)$ and day $30(P<0.05)$ had also higher ratios of $C 12 O$ to bacterial $16 \mathrm{~S}$ rRNA gene abundance.

Community Compositions of $n a h$ and $C 12 O$ Genes in the Soil Microcosms

Four terminal restriction fragments (TRFs) of $n a h$ gene were obtained from restriction digestion of Rsa I and Alu I. The TRF of $325 \mathrm{bp}$ was the dominant group in all microcosms with a proportion ranged from 53.22 to $76.10 \%$ (Fig. $4 a$ ). The PERMANOVA analysis showed the significant differences in T-RFLP profiles of $n a h$ gene between DOM treatments $(P=0.0001$, pseudo- $F=12.25)$ and also between incubation time $(P=0.0001$, pseudo- $F=12.25)$. Pair-wise test using PERMANOVA revealed highly significant differences in community composition of nah gene between in DOM treatments and in the control ( $P=0.0001$ for all). Community composition of $n a h$ gene in treatment WS also significantly differed from both MCSW and CM $(P=0.022$ and $P=0.0078$, respectively) (Fig. 4b). The T-RFLP profile of nah gene showed the obvious variation that the portion of $325 \mathrm{bp}$ of nah TRFs increased while that of $221 \mathrm{bp}$ was in a contrary trend in microcosms treated with DOMs than the control (Fig. 4a).

Ten TRFs of $C 12 O$ gene were acquired from restriction digestion of Msp I. The TRFs of 139 and $97 \mathrm{bp}$ were the dominant groups in the soil microcosms (Fig. 4c). The significant differences in T-RFLP profiles of $C 12 O$ gene between DOM treatments $(P=0.0001$, pseudo- $F=11.742)$ and also between incubation time $(P=0.0001$, pseudo- $F=2.2551)$ were presented by the PERMANOVA analysis. Pair-wise test using PERMANOVA showed the significant differences in community composition of $C 12 \mathrm{O}$ gene between all of the treatments ( $P=0.0002$ for between treatment WS and MCSW; $P=0.0001$ for others) except for between treatment $\mathrm{CM}$ and the control (Fig. 4d). T-RFLP profile of $\mathrm{C} 12 \mathrm{O}$ gene showed that the proportions of the prevalent TRFs 139 and 97 bp changed in different ways in treatments WS and MCSW compared with the control during the whole incubation. The proportion of $97 \mathrm{bp}$ increased during the whole incubation while that of $139 \mathrm{bp}$ firstly decreased and then recovered slowly in treatments WS and MCSW compared with the control (Fig. 4c).

Phylogeny of nah and $\mathrm{C} 12 \mathrm{O}$ Genes in the Soil Microcosms

A total of 77 nah gene sequences from the initial soil were assigned into 10 OTUs. The representative sequences from each OTU, which contained all of the nah TRFs types, were used for the phylogenetic analysis. The results indicated that all of $n a h$ clones were affiliated within Gammaproteobacteria (44.16 \%) and Betaproteobacteria (59.84 \%). The clones of 260- and 221bp TRFs were assigned to Gammaproteobacteria, while those of 325- and 92-bp TRFs were assigned to Betaproteobacteria 

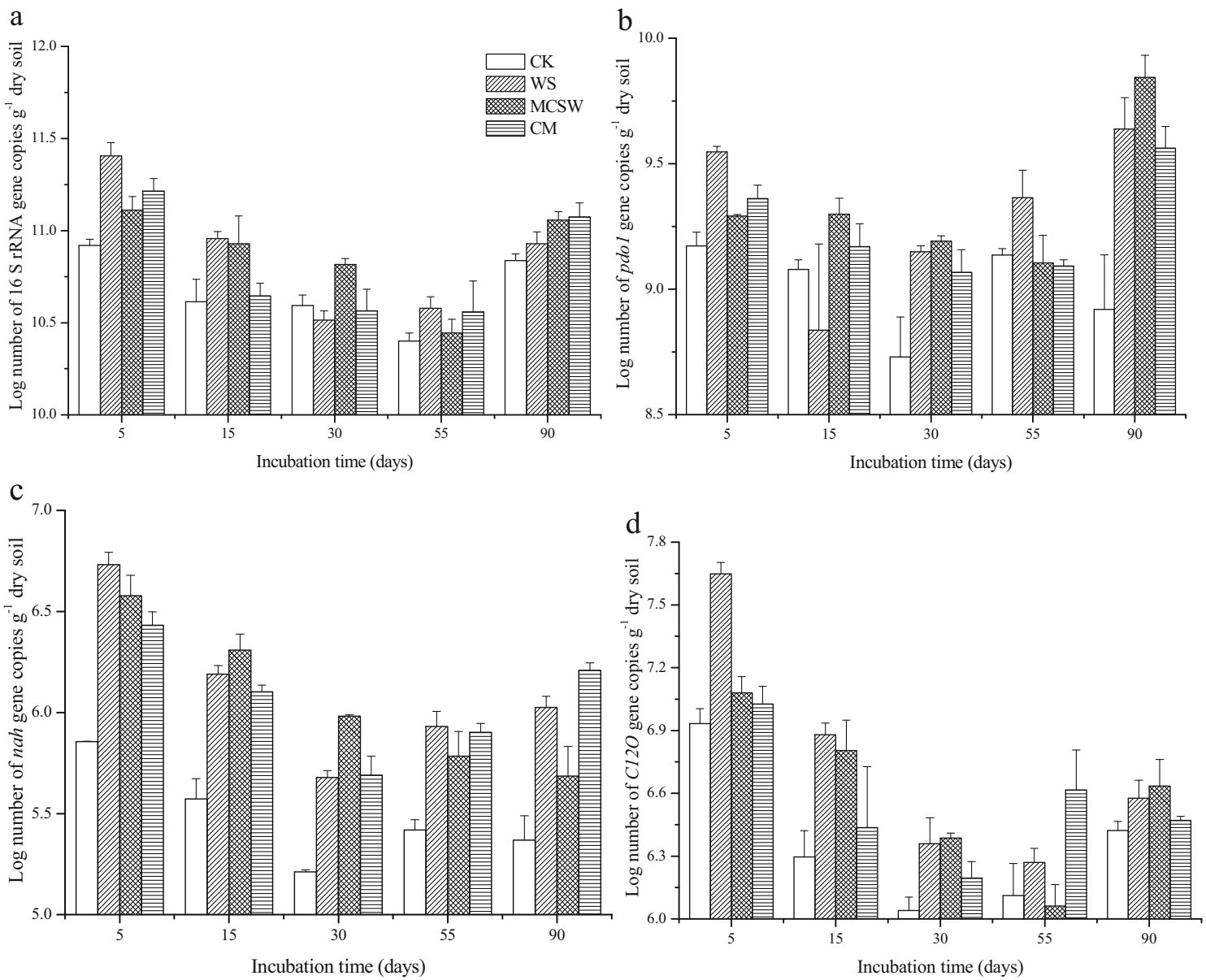

Fig. 3 Abundances of the 16S rRNA (a), pdol (b), nah (c), and C12O (d) genes in microcosms at different incubation periods. CK, WS, MCSW, and CM represent the control and the treatments with DOMs

from wheat stalk, mushroom cultivation substrate waste, and cow manure, respectively. Error bars are the SD of $n=3$. The data were analyzed using repeated measure ANOVA

(Fig. S1a). The result of clone library of $n a h$ gene was consistent with its T-RFLP profile that the TRF of $325 \mathrm{bp}$, which was assigned to Betaproteobacteria, was the dominant group in all the soil microcosms.

The clone library of $\mathrm{C} 12 \mathrm{O}$ gene included 218 positive clones, which were assigned into 27 classes. The representative sequences from each of classes, which covered all of the $\mathrm{C12O}$ TRFs types, were used to analyze the phylogeny. Results showed that all of $\mathrm{C} 12 \mathrm{O}$ clones were assigned into five groups, i.e., Gammaproteobacteria (50 \%), Betaproteobacteria (11.48 \%), and three unknown groups (38.52\%). All the C12O TRFs, except 210 bp that only emerged in Gammaproteobacteria, 110 bp that only emerged in Betaproteobacteria, and 92- and 194-bp TRFs that only emerged in group 2, existed in multiple groups. The dominant TRF of $139 \mathrm{bp}$ was found in all groups except group 1. In detail, however, 88 of 93 TRFs of 139 bp existed in Gammaproteobacteria. Furthermore, the 12 of 17 TRFs of $97 \mathrm{bp}$ were also found in Gammaproteobacteria. The 9 of 15 TRFs of 86 bp were assigned within Betaproteobacteria. The eight of nine TRFs of $157 \mathrm{bp}$ existed in group 1. The 33 of 34 TRFs of $122 \mathrm{bp}$ were affiliated in group 3. In a total of nine TRFs of
$83 \mathrm{bp}$, seven TRFs were classified into group 3 (Fig. S1b). The result of the clone library that Gammaproteobacteria were primary bacteria harboring $\mathrm{C} 12 \mathrm{O}$ gene was consistent with its TRFLP profile that the TRFs of 139 and $97 \mathrm{bp}$, which were mainly assigned to Gammaproteobacteria, were the dominant group in all the soil microcosms.

\section{Discussion}

The DOMs derived from agricultural wastes were nontoxic biosurfactants and can be utilized preferentially by soil microorganisms. The application of various DOMs was anticipated to offer dual advantages of enhancing the mobility of hydrophobic organic contaminants and increasing the nutrients for indigenous soil microorganisms [11]. As expected, the addition of DOMs significantly hastened the dissipation of PAHs in microcosms since 15 days of incubation in this study. Therefore, the application of DOMs to soil was considered as a useful measure to alleviate the soil PAH contamination. However, significant difference in alleviating soil contamination with PAHs was also 

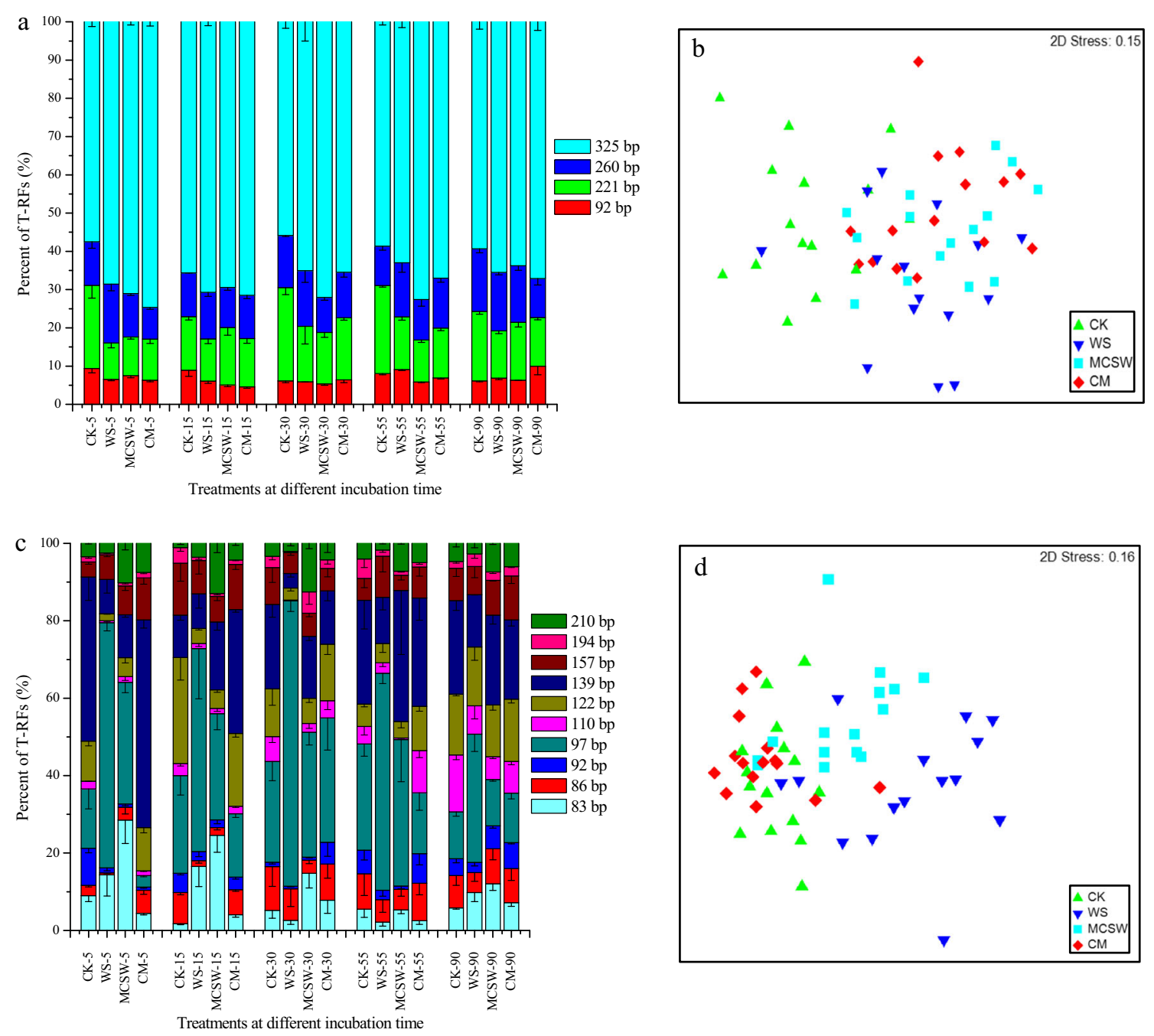

Fig. 4 T-RFLP patterns of $n a h$ (a) and $C 12 O$ (c) genes in microcosms at different incubation periods and NMDS plots on the basis of Bray-Curtis similarity indices of fourth-root-transformed T-RFLP data of nah (b) and $\mathrm{C} 12 \mathrm{O}$ (d) genes in different treatments. CK, WS, MCSW, and CM

found among the microcosms treated by different types of DOMs in the later period of the incubation experiment. The contents of remaining PAHs were significantly lower in both the treatments MCSW and CM than the treatment WS on days 55 and 90 . This could be due to the higher proportion of hydrophobic fraction in DOM-MCSW and DOM-CM than DOMWS. The early studies had suggested that PAHs had more pronounced interactions with DOM containing more hydrophobic moieties of organic macromolecules [31, 32]. Thereby, the soils amended with DOMs containing higher proportion of nonpolar parts could be more effective in PAH biodegradation. In addition, low-molecular-weight (LMW) PAHs were found to be more easily eliminated than high-molecular-weight (HMW) PAHs. It is commonly acknowledged that the aqueous solubility and bioavailability of PAHs decrease with increasing number of aromatic rings; thus, LMW PAHs were conducive to microbial degradation compared to the HMW PAHs [2]. represent the control and the treatments with DOMs from wheat stalk, mushroom cultivation substrate waste, and cow manure, respectively. -5 , $-15,-30,-55$, and -90 mean the incubation periods of $5,15,30,55$, and 90 days. Error bars are the SD of $n=3$

Many studies had demonstrated that indigenous microbial communities played an important role in attenuation of organic contaminants in soils $[33,34]$. As degradation of organic contaminants was dependent on microbial activity, abundance, and composition of microbial population with the corresponding functions, the accelerated biodegradation of PAHs in DOM-treated soils was expected to be explained by the changes of aboriginal PAH-degrading microbial population. In this study, the application of DOMs significantly increased abundances of all the detected genes, even though the degree of improving the microbial growth varied in different treatments and incubation time. And, the ratios of abundances of different PAH-degrading genes to bacterial 16S rRNA gene in some DOM-treated soils were significantly higher than that in the control on some incubation time. It indicated that addition of DOMs was an important driving force to stimulate the growth of bacteria especially those responsible for the 
degradation of PAHs. The difference of PAH diffusion among the treatments added by various DOMs could be illuminated by the corresponding development of PAH degraders. No significant difference of PAH elimination was observed among the treatments with various DOMs before 15 days of incubation, though DOM-WS contained lower proportion of hydrophobic fraction than DOM-MCSW and DOM-CM. It was presumably the result of high abundance of PAH degraders in the treatment WS on day 5. After that, the diminishing advantage of the amount of microbial degraders led to the subsequent slow removal of PAHs in treatment WS. In addition, there was similar content of remaining PAHs in treatments MCSW and CM on day 55, while treatment MCSW exhibited the higher degradation of PAHs than treatment CM at the end of incubation. It seemed to be unreasonable because the DOM-MCSW had lower proportion of hydrophobic part than DOM-CM. However, it could be explained from a perspective of microbial consortia. In this study, abundance of Mycobacterium in treatment MCSW was highest on the last sampling time. The simultaneous appearance of high degradation of PAHs and more Mycobacterium in treatment MCSW implied that Mycobacterium may play an important role in removal of remaining PAHs in the later period. The remarkable growth of Mycobacterium in the later period of incubation, when the added DOM was estimated to be almost consumed, showed the competitive advantage of Mycobacterium under oligotrophic conditions. A series of studies had demonstrated that Mycobacterium was an excellent candidate for regulating aged PAH-polluted soils due to the traits of lipophilic surfaces, biosurfactant production, and efficient catabolization toward PAHs up to five benzene rings [35-38].

The profiling analysis of microbial communities can contribute to identify the members of potential PAH-degrading microbial consortia and understand the patterns of microbial responses to external stimuli in polluted soils $[14,39]$. In this study, all nah clones were affiliated within Gammaproteobacteria and Betaproteobacteria. In contrast to the $n a h$ clone library, sequences of the $\mathrm{C} 12 \mathrm{O}$ clone library showed higher diversity and numerous sequences presented only low similarity to sequences deposited in GenBank database. Even so, most of $C 12 \mathrm{O}$ clones were still related to Gammaproteobacteria and Betaproteobacteria. It indicated that Gammaproteobacteria and Betaproteobacteria could be important microbial degraders of PAHs in soils [3, 40]. PERM ANOVA analyses on T-RFLP profiles showed that addition of DOMs and incubation time exerted the significant influence on community compositions of both nah and $\mathrm{C} 12 \mathrm{O}$ genes. Community compositions of $n a h$ and $C 12 O$ genes significantly varied between most of treatments, suggesting that addition of DOMs was a key factor influencing $\mathrm{nah}$ and $\mathrm{C12O}$ community compositions. Highly significant differences in community composition of nah gene between in DOM treatments and in the control were observed. Significant differences in community composition of $n a h$ gene were also found between the treatments added by various DOMs. It indicated that addition of DOMs had a significant effect on community composition of nah gene and the DOMs originated from various agricultural wastes usually influenced the nah gene community in their own ways. The remarkable changes in community composition of $C 12 O$ gene between all of the treatments except between treatment $\mathrm{CM}$ and the control were found. It indicated that DOM-WS and DOM-MCSW significantly changed the community composition of $\mathrm{C} 12 \mathrm{O}$ gene, while DOM-CM did not significantly influence the $\mathrm{C} 12 \mathrm{O}$ gene community composition. Similar results have been reported by Li et al. [18]. They found that addition of mushroom cultivation substrate significantly increased abundance of the bacteria, fungi, and aromatic hydrocarbon degraders in PAHcontaminated soil and had a varying impact on bacterial and fungal community. In summary, although the DOMs affected PAH-degrading genes in different ways, it suggested that external stimuli produced by DOMs enhance the microbial degradation of PAHs in soils through not only solubilizing PAHs but also altering abundance and composition of indigenous microbial degraders [14].

In conclusion, this study provided a novel insight into the modulation of DOMs on microbial remediation of PAHcontaminated soils. The results could be explained not only by the properties of various DOMs but also by the size of PAH degraders and their composition which changed during the remediation of PAH-contaminated soils. Expectedly, all treatments amended with DOMs significantly hastened the dissipation of PAHs in the soil microcosms, and DOMs containing higher proportion of hydrophobic fraction could promote the elimination of PAHs more effectively than that with lower proportion of hydrophobic fraction. The addition of DOMs significantly increased abundances of the bacterial $16 \mathrm{~S}$ rRNA and all of the detected PAH degrading-related genes. The community compositions of the nah and $\mathrm{C12O}$ also varied among different treatments and incubation time in different ways. Mycobacterium harboring pdol gene and Gammaproteobacteria and Betaproteobacteria harboring $n a h$ and $\mathrm{Cl} 2 \mathrm{O}$ genes were considered as the important potential PAH degraders. Our findings are anticipated to reinforce the understanding how the DOMs modulate microbial degradation of PAHs in soils. However, more studies are needed to confirm these conclusions through analyzing more diverse PAH-degrading genes or microorganisms using RNA-based, DNA-SIP, and other advanced methods.

Acknowledgments This study was financially supported by the Natural Science Foundation of China $(41301567,51221892,21207049)$ and the International Cooperation Training Project Funding for Outstanding Middle-aged and Young Backbone Teachers in Colleges and Universities of Shandong Province. We are grateful to Dr. Qinzeng Xu of Institute of 
Oceanology, Chinese Academy of Sciences, for his assistance in data analysis.

\section{References}

1. Johnsen AR, Wick LY, Harms H (2005) Principles of microbial PAHdegradation in soil. Environ Pollut 133:71-84

2. Peng RH, Xiong AS, Xue Y, Fu XY, Gao F, Zhao W, Tian YS, Yao $\mathrm{QH}$ (2008) Microbial biodegradation of polyaromatic hydrocarbons. FEMS Microbiol Rev 32:927-955

3. Niepceron M, Martin-Laurent F, Crampon M, Portet-Koltalo F, Akpa-Vinceslas M, Legras M, Bru D, Bureau F, Bodilis J (2013) Gamma Proteobacteria as a potential bioindicator of a multiple contamination by polycyclic aromatic hydrocarbons (PAHs) in agricultural soils. Environ Pollut 180:199-205

4. Alcántara MT, Gómez J, Pazos M, Sanromán MA (2008) Combined treatment of PAHs contaminated soils using the sequence extraction with surfactant-electrochemical degradation. Chemosphere 70:14381444

5. Antizar-Ladislao B (2010) Bioremediation: working with bacteria. Elements 6:389-394

6. Librando V, Pappalardo M (2013) In silico bioremediation of polycyclic aromatic hydrocarbon: a frontier in environmental chemistry. $\mathrm{J}$ Mol Graph Model 44:1-8

7. Northcott GL, Jones KC (2001) Partitioning, extractability, and formation of nonextractable PAH residues in soil. 1. Compound differences in aging and sequestration. Environ Sci Technol 35:1103-1110

8. Luo L, Lin S, Huang HL, Zhang SZ (2012) Relationships between aging of PAHs and soil properties. Environ Pollut 170:177-182

9. Kobayashi T, Murai Y, Tatsumi K, Iimura Y (2009) Biodegradation of polycyclic aromatic hydrocarbons by Sphingomonas sp. enhanced by water-extractable organic matter from manure compost. Sci Total Environ 407:5805-5810

10. Cheng KY, Wong JWC (2006) Combined effect of nonionic surfactant Tween 80 and DOM on the behaviors of PAHs in soil-water system. Chemosphere 62:1907-1916

11. Marschner B, Kalbitz K (2003) Controls of bioavailability and biodegradability of dissolved organic matter in soils. Geoderma 113: 211-235

12. Yu H, Huang GH, An CJ, Wei J (2011) Combined effects of DOM extracted from site soil/compost and biosurfactant on the sorption and desorption of PAHs in a soil-water system. J Hazard Mater 190:883890

13. Mei Y, Wu FC, Wang LY, Bai YC, Li W, Liao HQ (2009) Binding characteristics of perylene, phenanthrene and anthracene to different DOM fractions from lake water. J Environ Sci (China) 21:414-423

14. Muckian LM, Grant RJ, Clipson NJW, Doyle EM (2009) Bacterial community dynamics during bioremediation of phenanthrene- and fluoranthene-amended soil. Int Biodeterior Biodegrad 63:52-56

15. Ringelberg DB, Talley JW, Perkins EJ, Tucker SG, Luthy RG, Bouwer EJ, Fredrickson HL (2001) Succession of phenotypic, genotypic, and metabolic community characteristics during in vitro bioslurry treatment of polycyclic aromatic hydrocarboncontaminated sediments. Appl Environ Microbiol 67:1542-1550

16. Vinas M, Sabate J, Espuny M, Solanas M (2005) Bacterial community dynamics and polycyclic aromatic hydrocarbon degradation during bioremediation of heavily creosote-contaminated soil. Appl Environ Microbiol 71:7008-7018

17. Meynet P, Hale SE, Davenport RJ, Cornelissen G, Breedveld GD, Werner D (2012) Effect of activated carbon amendment on bacterial community structure and functions in a PAH impacted urban soil. Environ Sci Technol 46:5057-5066
18. Li XZ, Wu YC, Lin XG, Zhang J, Zeng J (2012) Dissipation of polycyclic aromatic hydrocarbons (PAHs) in soil microcosms amended with mushroom cultivation substrate. Soil Biol Biochem 47:191-197

19. Cunliffe M, Kertesz MA (2006) Effect of Sphingobium yanoikuyae B1 inoculation on bacterial community dynamics and polycyclic aromatic hydrocarbon degradation in aged and freshly $\mathrm{PAH}-$ contaminated soils. Environ Pollut 144:228-237

20. Khan S, Heshan A, Qing G, Shuang L, He JZ (2009) Biodegradation of pyrene and catabolic genes in contaminated soils cultivated with Lolium multiforum L. J Soils Sediments 9:482-491

21. Tuan NN, Hsieh HC, Lin YW, Huang SL (2011) Analysis of bacterial degradation pathways for long-chain alkylphenols involving phenol hydroxylase, alkylphenol monooxygenase and catechol dioxygenase genes. Bioresour Technol 102:4232-4240

22. Han XM, Liu YR, Zheng YM, Zhang XX, He JZ (2014) Response of bacterial pdol, nah and $C 12 O$ genes to aged soil PAH pollution in a coke factory area. Environ Sci Pollut Res 21:9754-9763

23. Johnsen AR, de Lipthay JR, Sørensen SJ, Ekelund F, Christensen P, Andersen O, Karlson U, Jacobsen CS (2006) Microbial degradation of street dust PAHs in microcosms simulating diffuse pollution of urban soil. Environ Microbiol 8:535-545

24. Baldwin BR, Nakatsu CH, Nies L (2003) Detection and enumeration of aromatic oxygenase genes by multiplex and real-time PCR. Appl Environ Microbiol 69:3350-3358

25. Sei K, Asano K, Tateishi N, Mori K, Ike M, Fujita M (1999) Design of PCR primers and gene probes for the general detection of bacterial populations capable of degrading aromatic compounds via catechol cleavage pathways. J Biosci Bioeng 88:542-550

26. Lu RK (1999) Analysis methods of soil agrichemistry. China Agricultural Science and Technology Press, Beijing

27. USEPA (2000) Method 3550C, test methods for evaluating solid waste. EPA SW-846, 3rd edn. US Government Print Office, Washington

28. Lillis L, Clipson N, Doyle E (2010) Quantification of catechol dioxygenase gene expression in soil during degradation of 2,4-dichlorophenol. FEMS Microbiol Ecol 73:363-369

29. Lv BY, Xing MY, Yang J, Qi WS, Lu YS (2013) Chemical and spectroscopic characterization of water extractable organic matter during vermicomposting of cattle dung. Bioresour Technol 132: $320-326$

30. Song NH, Zhang S, Hong M, Yang H (2010) Impact of dissolved organic matter on bioavailability of chlorotoluron to wheat. Environ Pollut 158:906-912

31. Kukkonen J, McCarthy JF, Oikari A (1990) Effects of XAD-8 fractions of dissolved organic carbon on the sorption and bioavailability of organic micropollutants. Arch Environ Contam Toxicol 19:551557

32. Maxin C, Kogel-Knabner I (1995) Partitioning of PAH to DOM: implications on PAH mobility in soils. Eur J Soil Sci 46:193-204

33. Liang YT, Van Nostrand JD, Deng Y, He ZL, Wu LY, Zhang X, Li GH, Zhou JZ (2011) Functional gene diversity of soil microbial communities from five oil-contaminated fields in China. ISME J 5:403413

34. Block JC, Mathieu L, Servais P, Fontvieille D, Werner P (1992) Indigenous bacterial inocula for measuring the biodegradable dissolved organic carbon (BDOC) in waters. Water Res 26: 481-486

35. Wick LY, Ruiz de Munain A, Springael D, Harms H (2002) Responses of Mycobacterium sp. LB501T to the low bioavailability of solid anthracene. Appl Microbiol Biotechnol 58:378-385

36. Bogan BW, Lahner LM, Sullivan WR, Paterek JR (2003) Degradation of polycyclic aromatic and straight-chain aliphatic hydrocarbons by a strain of Mycobacterium austroafricanum. J Appl Microbiol 94:230-239 
37. Wells M, Wick LY, Harms H (2005) Model polymer release system study of PAH bioaccessibility: the relationship between rapid release and bioaccessibility. Environ Sci Technol 39: $1055-1063$

38. Uyttebroek M, Breugelmans P, Janssen M, Wattiau P, Joffe B, Karlson U, Ortega-Calvo JJ, Bastiaens L, Ryngaert A, Hausner M, Springael D (2006) Distribution of the Mycobacterium community and polycyclic aromatic hydrocarbons (PAHs) among different size fractions of a long-term PAH-contaminated soil. Environ Microbiol 8:836-847

39. Kennedy N, Edwards S, Clipson N (2004) Impact of lime, nitrogen and plant species on bacterial community structure in grassland microcosms. Environ Microbiol 6:1070-1080

40. Lors C, Ryngaert A, Périé F, Diels L, Damidot D (2010) Evolution of bacterial community during bioremediation of PAHs in a coal tar contaminated soil. Chemosphere 81:1263-1271 